\title{
ANALYSIS OF THE CONDITION OF THE LOW COST COMPANIES AND THEIR CONNECTION TO THE TOURISM DEVELOPMENT IN THE REPUBLIC OF MACEDONIA
}

DOI: http://dx.doi.org/10.18509/GBP.2017.22

UDC: 338.48:[656.7:338.534(497.7)

\author{
Hristina Dimeska \\ Nikola Panov \\ Department of Geography, Faculty of Natural Sciences and Mathematics, Sts. Cyril and \\ Methodius University, Macedonia
}

\begin{abstract}
The appearance of low-cost airline companies and with that the introduction of cheap flights caused an appearance of a new phase in the development of air traffic and the traffic in general.

These airline companies are offering their services for lower prices than the other airline companies, but as a result they have their own principles and some segments of their work can be expressed in positive or negative sense for the passengers.

The Republic of Macedonia is a country that is characterized by the slow tourism development with a lot of challenges and introduction of low cost airlines seems as a stepping stone in the tourism development and positioning on the tourism market, with an accent on European tourism market.

The goal of the paper is to establish whether the introduction of the low cost airlines influences the increase of the number of travelers, through the analysis of the data regarding the number of transported passengers after the introduction of these low-cost flights on the two airports in the country, Alexander the Great - Skopje and St. Paul the Apostle - Ohrid. Moreover, to conclude whether this indirectly leads towards an increase of the number of tourists, above all foreign tourists in Macedonia.
\end{abstract}

Keywords: low cost airlines, tourist's number, R. Macedonia

\section{INTRODUCTION}

The growth of low cost carriers in the world is arguably the single most important factor currently shaping the airline industry. Low budget airway companies slowly but surely take the primate in the airway industry and increase their representation relating to the overall number of transported passenger on local, regional and world level. These airline companies are most represented in the developed countries, although in the last decade they also represent a trend for developing countries. The number of users of these servers continuously rises and analogically to that, so does the representation of low cost air carriers on the airway transportation market. With this, their profit notes permanent growth, which is especially relatable since 2007 onwards, with the appearance of the economic crises and the bankruptcy of a large number of regular airline companies.

The entrance of these low cost air carriers in the region, including the Republic of Macedonia in 2011, brought one new wave in the development of the air transport, which inevitably contributed towards continuous growth of the number of travelers at the airports on one, and cost increase on the other hand. 
It is these companies performance in the region precisely what brought about the analysis of this paper, and the surrounding countries and the condition with the low cost carriers in the aforementioned are also analyzed and reviewed, in terms of the representation of the companies at the countries which have airports competitive to the Skopje airport, the price of the tickets of low cost carrier companies and regular companies, then the number of destinations of the airline, but also the number of transported passengers in timeframe depending on the availability of appropriate data.

\section{LITERATURE REVIEW AND METHODOLOGY}

Low cost carrier airline companies are slowly but surely anchoring in the airway transportation. Despite their impact on the overall airline industry, low cost companies have received very little attention in the economics literature. A few studies [5] have attempted to estimate the overall fare savings attributable to low cost companies. Other studies [3] have studied the impact level of low cost companies' entry on incumbent carriers. While low-cost carriers only carry $15 \%$ of the domestic traffic in the United States, their impact on prices is significant and broadly distributed over the marketplace. This paper defines the low-cost carrier to be an airline that operates a point-to-point network, pays employees below the industry average wage, and offers no frills service [7]. "Initially, low-cost carriers were successful because they were not about luring away customers, but instead they aimed for a new consumer group by offering cheaper tickets making those people able to travel by airplane that would otherwise not have flown because of financial reasons" [4].

As it can be noted, the low cost airlines made certain revolution in the airway traffic, and with that also over the touristic development of specific destinations. Finally, Low cost companies are responsible for 70\% of the 1995-2012 increase in the number of intraEuropean flights or seats and $64 \%$ of the seat-km [2].

However, it would be wrong to claim that the low-cost airlines can replace the scheduled airlines since today safety plays an important factor in selecting the air carrier. "Besides, the appearance of low-cost airlines has positively influenced the pricing policy of regular carriers who, whether they like it or not, have to introduce new tariff systems with significantly lower fares" [8]. There are at least two reasons why the launch of low cost flights should affect tourism positively. First, by improving the affordability of international flights low cost airlines might generate additional tourism demand, second, by operating towards minor airports, they could also play a role in boosting niche tourism markets in smaller regions, such as Macedonia.

New potential of the low cost airline companies were identified through extensive searches on the internet and in the literature. Then the list of potential newcomers was filtered by simulation booking and comparing prices with traditional airlines in the Republic Of Macedonia. Through this process, a list of all companies that are operating in the country was created.

The present research study takes as its research methodology or research design the analysis and synthesis of secondary sources of data and information due to the nature of the present study as discussed above. There are quite a few ways through which both the quantitative and qualitative research can be conducted. As of today, there are a number of research methods and designs which are approved by a number of social scientists and business research scholars. The sources are acquired from a number of different sources such as journals, books, research websites, recent and very latest surveys, the analyses of 
these surveys, official aviation websites, and websites of a number of airlines spreading over the entire globe and so on.

To represent the networks of low-cost airline carriers in the Republic of Macedonia, we had to create our own database in which the previously low-cost airline carriers and their network and destination properties were listed.

\section{LOW COST AIRLINES - PRINCIPLES OF WORK}

On American and European soil the first tries for lowering the prices of airplane tickets appear after WWII. However, the real change appeared in the U.S. in 1978, when the role of government in the airway companies was slowly marginalized, while in Europe the changes followed only after 1994 when new era of cooperation began, among the continental airway carriers to specific destination in the country, and it is only later when these flights appear on the "old continent" when the European laws allow for low cost carriers to fly out of the countries in which they are registered, meaning outside of their national market.

Today, these companies fly on all continents and in almost all world regions, and as an example we can take the data that says that in 2010, 94 low cost carrier companies were registered, carrying 650 million passengers, $(23,5 \%)$, operating 5.8 million flights (19\% of all regular flights) and serving 16,4 thousands routes (21,4\%) [1].

Of the low $4 \%$ in transported passengers in 1998, the number reached incredible $38 \%$ in 2010. In the period of 2004-2009 these aircraft companies note a growth of $18 \%$, compared to the regular aircraft companies that have growth less than $0 \%$. Low-cost carriers carried more than 950 million passengers in 2015, approximately $28 \%$ of total scheduled passengers [9].

\section{BASIC CHARACTERISTICS OF LOW COST AIRLINES}

The scientific and the broader public are both familiar with the main characteristics of low cost airlines, specific for them as a special category of air transport.

The basic characteristics are that these companies most frequently use the minor airports and much less the main ones (which is an exception in Macedonia) because they are much cheaper to serve the airlines themselves, the airport taxes are much lower too. They can be even 200-300 km away from the cities, but they have a positive influence of the work improvement of the secondary airports.

As a next characteristic of these low cost carriers appears the absence of sale saloons, so it is necessary to look for all the services online, if not that service is additionally charged. If it comes to canceling or rescheduling the flight, the airline company is not obligated to reimburse the services to the passengers.

Actually, what is sometimes thought of as the most meaningful characteristic of the low cost airline companies are the flexible terms for flying, that leave some space for delay of flights, but on the other hand the flights by these companies are usually at night and do not employ an easy connection to other flights.

Moreover, the length of the flight falls in this category, the space of the seats, the option to reserve certain seats is charged, the services in the aircraft are expensive and very importantly there is no possibility to cancel the reservation by the passenger.

The main advantage of these flights is of course their basic characteristic - the price of the ticket, but also the continuous growth of destinations from which these airplanes fly. In the public there is a belief that says that the prices of tickets will be even lower in future, but unfortunately this is not so, due to the fact that expenses of these companies 
increase. So, price of kerosene, air control expenses, airport, amortization, insurance expenses, aircraft maintenance, salary expenses, catering etc.

\section{LOW COST AIRLINES IN REPUBLIC OF MACEDONIA, ANALYSIS OF CONDITION, PERSPECTIVES AND TOURISM DEVELOPMENT}

Frequently, the tourism is represented as one of the instruments that initiate the local development of certain destinations, but as such he represents quite a specific category, conditioned by a number of factors, like the touristic values that the destination may offer, but also the remaining factors significant for the tourism, like the traffic connectivity. One of the ways to have easy accessibility is of course the high level of development of the airline traffic. If this is regarding a destination that is connected by operating low cost carrier airline companies, then the possibility of touristic development of the aforementioned destination increases.

A higher number of experts claim that establishing the influence of the low cost carriers in specific touristic destination is an empirical question, still in this paper an effort has been made to represent the findings as realistically as possible, that are connected to low cost airline companies and their work start in the Republic of Macedonia, as well as the viability of the government subsidies to some of them. The accessible data relating these exact flights are utilized in the paper.

At the beginning these companies operated only in the developed countries. Above all the western countries, and only afterwards with the acceptance of new members from Eastern Europe into the European Union and adopting of the legislation in the countries that have not yet joined, has led to the introduction of new routes of low cost airlines. The period from 2004 to 2006 saw the introduction of the routes towards Bulgaria, Slovenia, Poland, Hungary, The Czech Republic, Turkey, and only afterwards follows the Republic of Macedonia in 2011 and at the beginning the Skopje airport, Alexander The Great and only later in the Ohrid's St. Paul the Apostle airport. When it comes to the Republic of Macedonia and the civil air traffic, the Law on Civil Aviation stands out, and the changes that influence the liberalization of air traffic in the country, adopted in 2006 when the abovementioned was set in accordance to the laws of the European Union regarding the civil aviation, which leave room for novelties in the air traffic.

The official entrance of the low cost airline carriers in the country happened in September 2011, when the first flight by the Hungarian Wizz Air was scheduled, relating from Skopje to Luton (London) airport, and the rest of the flights were to Milano, Malme, Munich, Dortmund and Basel. The aforementioned company has been chosen and the Macedonian government had set aside 306 million denars for two times, as subsidies for the low cost airline carriers for the periods of 2012-2015 and 2015-2018 which was foreseen to contribute to, and it also had an influence in attracting foreign tourists and foreign investments from one, but also increasing the number of travelers that visit European capitals from the other hand [9].

This period the Skopje airport is connected with 29 airlines, while in Ohrid, as a most meaningful touristic center in this country, 8 airline companies are operating, out of which one is low cost carrier (subsided) airline. The local self-government had set aside 3.100.000 MKD from its budget, in the period 2015-2018 to subsidy the line OhridLondon. These flights are of exceptional importance for the tourism not only in Ohrid as a most important summer Macedonian touristic destination, including the Ohrid coastline, but also for the whole Southwestern region. The Hungarian Wizz Air is the one operating this line, and according to the contract, it has the obligation to promote Ohrid as a touristic 
destination throughout the world, and to bring foreign tourists, the prognosis is that in the next three years Ohrid should be visited by 25.000 English people.

Besides the popularity of the subsidies for the low cost airlines, the idea for introduction of a national airline is also famous, and there was a feasibility study prepared by Dutch experts, that gave a negative answer to the justification because of high expenses but also the non-existence of sustainable conditions for that process. However, it was pointed out that there are no interferences between the establishment of a national airline and the subsidies of the low cost carriers. The market in the republic of Macedonia in this sphere is liberal and the success of the work of every operator depends on the way of management of the needs of Macedonian travelers and the interest for different destinations.

Republic of Macedonia as a touristic destination, keeping in mind the potentials it has at its disposal presents a competitive destination, although the region has also Greece, Bulgaria, Serbia, Montenegro, Kosovo but also Albania, which the last few years notes continued touristic development. Still, relating the competitiveness of the airports, probably the airport in Prishtina would be most appropriate to analyze. Kosovo which according to the scope and travelers dynamics, the number of destinations but also the number of operating airline companies, like regular so also low cost carriers is competitive to the Skopje airport. This period, the Prishtina airport has 25 airlines that are operating, out of which 8 are low cost carriers, while the overall number of destinations connected to Prishtina is 19.

When analyzed, the data that relate the number of travelers at the Skopje airport in the period when it is consessioned by Turkish TAV airport, [9] it is noted that in 2010 the number of passengers at the Skopje airport increased by $76.7 \%$, that is from 684.905 passengers in 2010, to 1.210 .509 in 2014. Together at the both airports, for the past five years, the total growth is $75 \%$, or from 729.297 passengers in 2010 , to 1.278 .343 passengers in 2014. Followed by years, in 2013 the same grew for 236\%, and in 2014 over 500.000 million of passengers were transported or 50\% more compared to 2013. In 2015 growth of $22 \%$ was evidenced, regarding the overall number of travelers at the two Macedonian airports, reaching a number of 1.560.381 traveler. At the same time, the total number of air lines was 15.510 , with an increase of $11 \%$ on yearly level. Total 1.794.376 travelers travelled through the two Macedonian airports in 2016, which is an increase of $75 \%$ compared to 2015. In 2016, there is an appearance of increase of the capacity, which is $22 \%$ compared to 2015 . The last year, 2016, was a very successful year for increase of the traffic of the airport in Ohrid, where the number of passengers grew for $39.2 \%$ at an annual level, which gave a reason to the Airport Council International ACI, to proclaim the airport St. Paul the Apostle for an airport with quickest growth in its category, in the last few quarters. According to the data for travel traffic, Istanbul, (with the two airports Ataturk and Sabiha Gokcen) is the most frequent destination of the airport Alexander the Great - Skopje in 2016, with 12,6\% of market contribution, then Zurich with 10,2\%, Wien - 6,3\%, Basel - 5\%, Malme - 4,8\% and London with 4,3\% market contribution. Regarding the airline companies, Wizz Air has transferred the highest number from the travelers, with 54,8\% market contribution, then comes Turkish Airlines, Austrian Airlines, Germania Flug, Pegasus Airlines, Edelweiss. The low cost carrier Wizz Air notes growth of 5,6\%, in 2016 compared to 2015, when 49,2\% of market contribution were noted at the two Macedonian airports. Wizz Air offers low cost routes to 24 destinations from the Skopje and Ohrid airport, connecting the Macedonian citizens with 11 countries. 


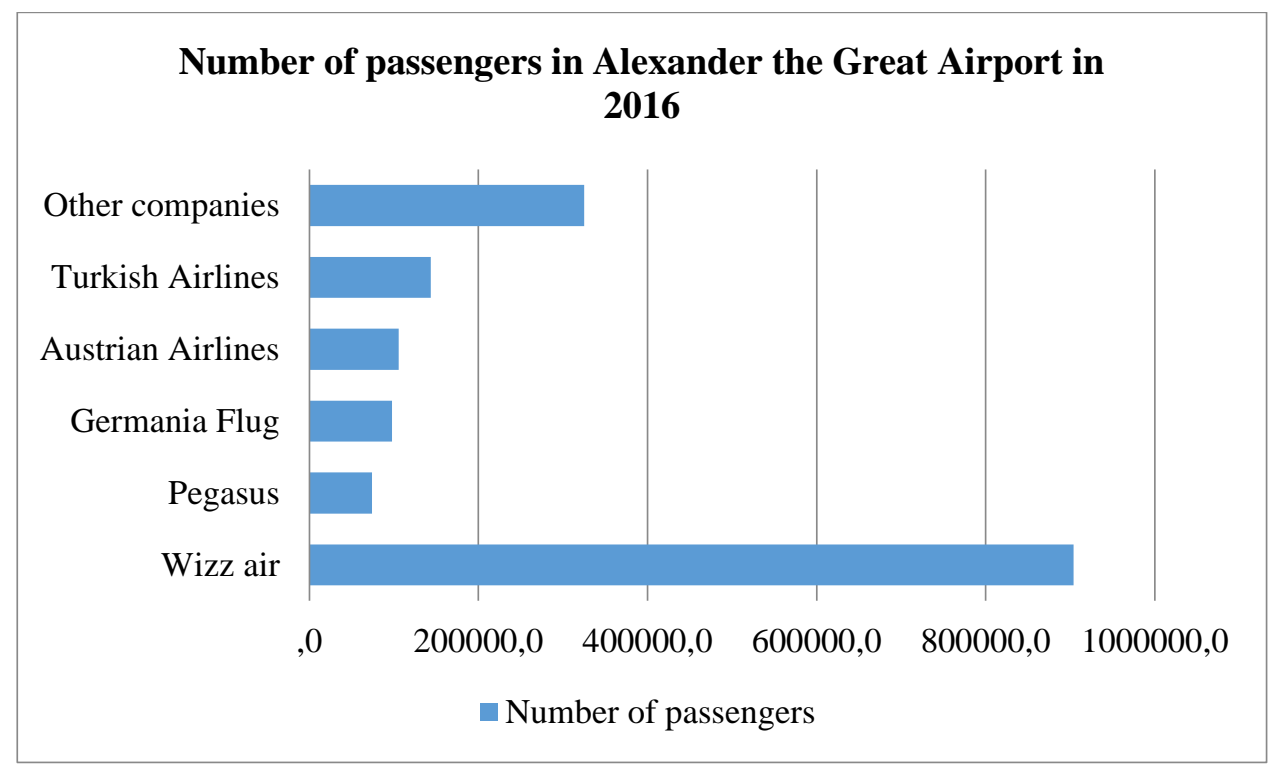

Figure 1. Number of transferred travelers by airline companies for 2016, at the Alexander the Great airport

The analysis of the number of travelers in 2016, points the overall number 1.649.374 travelers, the biggest part, 54,8\% traveled with Wizz Air, Turkish Airlines follows with 8,70\%, Austrian Airlines with 6,4\%, Germania Flug with 5,9\%, Pegasus with 4,5\% and the remaining other airline companies which take part with $19,7 \%$.

When the situation with the Macedonian air traffic is analyzed, it poses the question whether the proportional growth of the number of travelers at the Macedonian airports and the growth the number of tourists are connected and whether the increased number of travelers implies growth of evidenced tourists in the Republic of Macedonia.

It has been noted that a growth in the number of tourists appears within the analyzed period, so in 2012 there were 23,7\% more tourists than 2007, or 99,1\% more than 2001 . According to statistical data, in 2012 Macedonia was visited by 351,359 foreign tourists, and in 2013 this number increased for over $15 \%$.

The number of overnight stays of foreign tourists also increased, and the positive trends in tourism continue. The number of guests was higher for $4.8 \%$ in 2014 compared to 2013. There is $6.4 \%$ growth of foreign tourists, and $2.7 \%$ of domestic tourists. In 2015 , the number of tourists increased for $10.9 \%$ compared to 2014: there is an increase in domestic tourists for $6.5 \%$, and foreign tourists increase for $14.2 \%$. In 2016, compared to the same period from the previous year, the number of tourists increased for $5.0 \%$ and there is an increase of $5.1 \%$ of foreign tourists.

The given data point out to a certain connection of the introduction of low cost airlines and the growth of number of travelers with the growth of the number of foreign tourists in this country, but the fact that there is a global appearance of continued growth in tourism and touristic movements cannot be ignored, which analogically has influence over the increase of the number of tourists in Macedonia.

In 2016, Wizz Air, the biggest airline company in Macedonia, transferred over 1 million travelers on the low-tariff Macedonian routes, which represents growth of $27 \%$ on an annual level and supports more than 750 local work positions in related industries, offering 29 lines to 13 countries from the both Macedonian airports: in Skopje and in Ohrid. 


\section{CONCLUSION}

The airline industry has seen a tremendous change in trend in the 1990s when the lowcost carriers picked up pace in the market. This new type of air travel not only created a different passenger market across the U.S., Europe, and elsewhere, it also attracted the already in-line consumers like business travelers because of their attractive services and more importantly because of their much cheaper strategies to sell flight tickets. Continued growth is likely to be the primary driving force behind the future evolution of the airline industry in the coming years.

Republic of Macedonia notes a trend of increase of the number of travelers at the civil airports for the past few years, which is a result primarily on the investments in the renovation of the airports, introduction of new lines, the connection to a larger number of destinations and of course the most important factor, the entrance of the low-cost airline companies and the introduction of the cheap flights that are 35-70\% with lower prices of the airline tickets compared to the regular airline companies, and which connect Macedonia with a bigger number of destinations on a continental level.

One of the reasons for these companies' entrance in the region, and on Macedonian sky and their subsidies, is the need of cheap flights for the citizens of the Republic of Macedonia, but also the attraction of foreign tourists. Identifying the influence that these flights have over the increase of the number of tourists and with the development of tourism over certain destinations is a very complex process. In continuance, increase of the number of tourists in the country was noted, above all of the ones that are coming from abroad, which besides the trend of growth of the number of tourists globally, still points to the connection of the cheap flights to the increased number of tourists that visited this country and which shows to the data that there should be a strive towards attracting low-cost airline companies that would connect Skopje and Ohrid with those destinations that have initial potential compared to attracting tourists in the country which is especially important for the development of specific selective forms of tourism, like urban and cultural tourism in the capital.

\section{REFERENCES}

[1] Berster, P. \& Gelhausen, M. \& Wikien, D. Demmand and supply development patterns of low cost carriers in Africa, America, Europe, Australia and Asia. Paper presented at the 16th ATRS World Conference, Tainan, Taiwan, 2012;

[2] Dobruszkes, F. The Geography of European low-Cost airline networks: a contemporary analysis, Journal of Transport Geography, United Kingdom, vol 28, pp 7588, 2013;

[3] Dresner, M. \& Windle, R. Competitive Responses to low cost carrier entry, Transportation Research E, United Kingdom, vol 35 pp 59-75, 1999;

[4] Franke, M. Competition between network carriers and low-cost carriers - retreat battle or breakthrough to a new level efficiency? Journal of Air Transport management, United Kingdom, vol 10, pp 15-21, 2004;

[5] Morrison, S. A. Actual, Adjacent and Potential Competition: Estimating the full Effect of Southwest Airlines, Journal of Transport Economics and Policy, United Kingdom, vol 35, pp 239-256, 2001;

[6] Official Gazette of the Republic of Macedonia, No 70 of September 2001; 
[7] Sungkard, K. Low-Cost Carriers and Low Fares, www.bu.ac.th/knowledgecentre /epaper/july_dec2004/sungkard.pdf Thailand Transport Portal. 2012. http:// vigportal .mot.go.th/portal/site/PortalMOTEN/bout/aot-en, 2004;

[8] Vidovic A. \& Steiner S. \& Babic S.R. Impact of low-cost airlines on the European air transport market, 10th International Conference on Traffic Science ICTS 2006, Slovenia, 2006;

[9] Url-1 < http://www.airports.com.mk/default.aspx?ItemID=345q>, Retrieved time: 01, $02,03.2017$ 